\title{
Internacionalização e ação social: o caso da Construtora Norberto Odebrecht
}

\section{Internationalization and Social Practice: The Case of Construtora Norberto Odebrecht}

\author{
Ian Kisil Marino \\ Universidade Estadual de Campinas, Brasil \\ https://orcid.org/0000-0002-6584-834X \\ iankmarino@gmail.com \\ Pedro Giovannetti Moura \\ Universidade de São Paulo, Brasil \\ https://orcid.org/0000-0003-0104-6417 \\ pedrogimoura@hotmail.com
}

\section{RESUMO}

A Construtora Norberto Odebrecht (CNO) está presente em mais de 40 países, conformando-se como peça-chave no projeto de internacionalização da Organização Odebrecht, um dos maiores conglomerados empresariais do Brasil. Nesse contexto, propomos uma análise das intersecções entre a internacionalização da CNO e a sua ação social sem finalidades diretamente lucrativas, vista por nós como uma constante. A partir de uma análise ampla do processo, abordamos diversos países e momentos desse tipo de intervenção. Com isso, almejamos desenhar um estudo de caso, identificar 
seus referenciais históricos mais extensos e destacar que a ação social empresarial da CNO é parte essencial da sua estratégia de sucesso, remetendo aos preceitos do terceiro setor e do neoliberalismo.

Palavras-chave: Odebrecht, terceiro setor, história empresarial, história econômica.

Códigos JEL: F23, H32, L10.

\section{ABSTRACT}

Construtora Norberto Odebrecht (CNO) is present in over 40 countries, consisting of a key player in the internationalization project of the Odebrecht Organization, one of the largest business conglomerates in Brazil. We propose an analysis of the intersections between CNO's internationalization and social practice deprived of directly profitable purposes, which we perceive as a constant action. Seeking a broad analysis of the process, we cover several countries and moments in which this type of intervention occurred. This way, we seek to design a case study, identifying its most extensive historical references and highlighting that CNO's corporate social practice is an essential part of its successful strategy, which refers to the precepts of the third sector and neoliberalism.

Keywords: Odebrecht, third sector, business history, economic history. JEL Codes: F23, H32, L10.

\section{INTRODUÇÃO}

O objetivo deste texto é compreender o processo de construção de um modelo de internacionalização empresarial intrinsecamente vinculado à promoção de ações de impacto social presumidamente não lucrativas, a partir da experiência da Construtora Norberto Odebrecht (CNO). A CNO, nesse sentido, serve de estudo de caso, dada a sua intensa presença e a sua relevância nos cenários empresarial e econômico continentais recentes. Os exemplos elencados neste artigo sinalizam o enlace entre construções milionárias e ações sociais pontuais. Percebidas a proximidade e a reincidência dessas ocorrências, refletimos sobre questões como: qual a motivação para a ação empresarial de impacto social sem finalidade diretamente lucrativa? 
Quais as relações de interesses entre a internacionalização empresarial e a sua ação social? Esses projetos, de fato, podem ser considerados não lucrativos? A história da internacionalização da CNO é particular ou serve de exemplo para um aspecto da história empresarial e global contemporâneas do qual ela é apenas um caso?

Para responder a essas questões, propomos elucidar a trajetória da internacionalização da CNO de uma forma ampla, com as lentes voltadas para a sua atuação na América Latina. Não buscamos aprofundar ou esgotar a pesquisa histórica cronológica desse recorte nem mesmo adentrar os detaIhes das particularidades de cada caso. Com o intuito de contribuir para o debate, objetivamos, sobretudo, traçar as linhas mais extensas desse longo processo, contribuindo com a historiografia empresarial recente - ainda relativamente pouco explorada no âmbito regional.

Metodologicamente, realizamos um estudo empírico a partir da crítica de documentos produzidos pela empreiteira - particularmente, a revista institucional Odebrecht Informa, relatórios anuais e conteúdos digitais do website brasileiro e das suas versões estrangeiras.' Procuramos cotejar e discutir o resultado do trabalho empírico com uma literatura teórica especializada na interpretação crítica do neoliberalismo e, particularmente, na temática do terceiro setor, a qual foi ainda pouco explorada no meio historiográfico e, por isso mesmo, oferece ricas e novas possibilidades analíticas à história empresarial contemporânea.

Na prática, é imperioso que a nossa atenção recaia sobre dois processos que se conjuram entre 1970 e 1990: primeiro, a história da Odebrecht, com as suas particularidades e as facetas que desvelam acerca do cenário empresarial brasileiro; segundo, a história da relação das empresas com a ação social, que também sofreu profundas alterações, epistemológicas e práticas, dos anos 1970 em diante.

\section{UM PROBLEMA REINCIDENTE}

Em 1979, 35 km a nordeste de Arequipa, no Peru, iniciou-se a construção da hidrelétrica Charcani V. A sua capacidade geradora, de 135 Mw,

\footnotetext{
Entre o período de pesquisa e a redação do artigo, bem como a sua publicação, a Holding Odebrecht passou por mudanças estruturais que acarretaram uma reestruturação de seus websites no âmbito internacional. Em decorrência disso, muitas das fontes digitais utilizadas foram desvinculadas de seus URLs originais. Quando possível, referenciamos capturas de tela arquivadas no Internet Archive, como forma de permitir acesso aos leitores.
} 
superava os $35 \mathrm{Mw}$ das demais hidrelétricas Charcani (I, II, III, IV e VI), suportando, por si só, a demanda média da região, de 60 Mw. A dificuldade técnica da obra é digna de nota: $95 \%$ do processo se daria de forma subterrânea, na Cordilheira dos Andes e nas encostas do vulcão Misti, uma região sujeita a abalos sísmicos na ordem de 10 graus ao dia (Revista Odebrecht Informa, 1980). Foi a primeira construção da CNO fora do Brasil.

A mobilização do projeto envolveu, além da CNO, agentes políticos dos Estados brasileiro e peruano: o acordo fez parte de uma declaração conjunta dos presidentes João Figueiredo e Morales Bermudes, durante visita deste ao Brasil, no bojo da "reafirmação da importância de se manter a integração dos países latino-americanos na luta por uma nova ordem econômica internacional" (Revista Odebrecht Informa, 1980, p. 10). A obra contou com aporte do Banco do Brasil, na ordem de 98 milhões de dólares.

A obra de Charcani, é constantemente evocada pelo Grupo Odebrecht. Para além do componente técnico, a hidrelétrica é tratada como uma espécie de "mito fundacional" pela empresa. Charcani foi o "jardim de infância" da construtora brasileira no exterior, segundo Marc Altit - líder da negociação para a assinatura do contrato no Peru e, hoje, responsável pelo Desenvolvimento de Negócios Internacionais na Companhia Brasileira de Projetos e Obras (Revista Odebrecht Informa, 1994). Metafórica ou literalmente, Altit tem razão: de 1979 em diante, a internacionalização da CNO alçaria voo, amadureceria no decorrer das décadas de 1980 e 1990, e alcançaria o auge nos anos 2000, com atuação em mais de 40 países e representações em cinco continentes.

Um ano após concluída a hidrelétrica, em 1988, foi lançada, no Peru, uma edição bilíngue do livro Arequipa. Com texto do jornalista, escritor e político Patrício Rey de Castro, ministro do Trabalho e da Educação do Peru no período em 1983 e 1984, e introdução do ex-presidente peruano José Luis Bustamante y Rivero, a obra reúne 394 imagens, a partir do projeto de José Antonio de Lavalle. Arequipa transmite a arquitetura, a natureza e a cultura andinas, em um acervo relevante sobre a identidade da região homônima. A obra foi financiada pela $\mathrm{CNO}$, que não buscou nenhum lucro com a sua venda, mas prestou homenagem à região que recebera a sua primogênita obra internacional (Odebrecht, n. d. b).

Sete anos depois, em 1995, na efeméride dos 15 anos da empreiteira no Peru, outro livro bilíngue foi lançado — novamente, sem finalidade lucrativa: Trujillo Precolombiano, composto de registros da arte produzida pelos 
habitantes das cercanias de Trujillo, antes do desembarque dos europeus no continente, em 1492. Obras de arte, arquitetura e utensílios domésticos representativos das culturas ameríndias são reproduzidos, com o apoio de análises históricas e de críticas de especialistas².

Também no Peru, a construtora chegou a atuar por meio de quatro concessionárias - a IIRSA Norte, IIRSA Sur, Ruta del Sol e Rutas del Lima -, explorando, em muito, a construção e a manutenção de rodovias ${ }^{3}$. Junto à ascensão das obras lucrativas, a multinacional brasileira financiou mais projetos não lucrativos, aparentemente avessos à sua área de atuação primordial. Um deles é ligado à Cordilheira Escalera, uma área de Conservação Regional Ambiental na Amazônia Peruana, com 150 mil hectares. Nela, o Grupo Odebrecht desenvolve um programa de gestão socioambiental que, entre outras ações, apoia a produção agrícola de 24 famílias de pequenos produtores que vivem no setor Urahuasha, produzindo café orgânico em minifúndios. Na região, passam 36 dos 955 km da rodovia IIRSA Norte, cujas obras estão sob a batuta do consórcio Concin, do qual participa a CNO. O projeto socioambiental, no entanto, não apresenta finalidade diretamente lucrativa.

Destacado aqui como exemplo inaugural, o caso peruano é paradigmático do processo histórico de internacionalização da CNO. Charcani, além de preceder todas as outras obras internacionais da empreiteira, fundou a paulatina construção de um modo de atuação característico da CNO — presente nas demais obras no continente e até fora dele. Esses livros foram feitos com o desígnio de serem bem-acolhidos nessas mesmas regiões, como mostram o uso das línguas locais e a preocupação em reconhecer e valorizar aspectos naturais, culturais e históricos como temáticas das obras. $O$ projeto agrícola da Cordilheira Escalera visava a um impacto econômico, ambiental e social significativo às comunidades que dele usufruiriam, como mostra a opção pelos minifúndios, pelas culturas orgânicas e pela produção familiar. Sem ignorar as particularidades e as naturezas diversas desses projetos, é possível observar suas semelhanças: todos visam ser socialmente significativos para as suas devidas regiões, todos foram viabilizados pela CNO e nenhum deles buscou lucro direto para a empreiteira brasileira. E, sobretudo: todos estiveram nitidamente próximos espacial e temporalmente das

2 O livro tem coordenação editorial de José Antonio Lavalle, traz textos de Jorge Quiñones, Guillermo de Orma, Raúl Apesteguía, Santiago Uceda e Ricardo Morales, além de fotografias e reproduções de Javier Ferrand e Fernando Salomón. (Odebrecht, n. d. b).

3 Por exemplo, a ampliação da capacidade das rodovias Tarapoto-Yurimaguas (2009) e Paita-Tarapoto (2011). Os dois projetos somam $1.041 \mathrm{~km}$ de rodovias e contam com 10 pontos de pedágio, conectando a Amazônia ao Pacífico. (Organización Odebrecht, 2014). 
realizações - sem dúvidas, muito lucrativas - que edificaram o processo de internacionalização da CNO.

\section{A ODEBRECHT E A SUA INTERNACIONALIZAÇÃO}

O início da história da CNO remonta a 1944, quando Norberto Odebrecht, que assumira a empresa de seu pai, realiza a renegociação, junto ao Banco da Bahia, da dívida de Emílio Odebrecht. A fundação da empreiteira se deu em um período de mudanças para a indústria brasileira da construção pesada: as obras realizadas entre o final do século XIX e começo do XX, por empresas predominantemente europeias (em especial, inglesas e francesas), concentravam-se no campo das hidrelétricas, do fornecimento de energia elétrica e, principalmente, na construção de ferrovias de interligação das zonas de cultivo de café para o litoral, contribuindo, dessa forma, com o complexo exportador cafeeiro. As décadas de 1930 e 1940, com a chegada de Getúlio Vargas e o consequente advento de políticas públicas que visavam à promoção da industrialização do país, marcariam o início de uma modificação nesse modelo (Draibe, 1985; Ferraz Filho, 1981).

A CNO surgiu nesse cenário, para preencher um certo vazio no ramo da construção pesada no Nordeste brasileiro. Em 1950, foi realizada a construção da Usina de Correntina, na Bahia, a primeira hidrelétrica da Odebrecht. Ela representava o tipo de atuação da empresa nas suas primeiras décadas de atividade: obras de pequeno porte localizadas especialmente no Nordeste. No início dos anos 1970, a CNO ocupava a 19a posição entre as maiores construtoras brasileiras. A partir de então, mudanças importantes - em muito, associadas com as frutíferas relações com o governo militar brasileiro - deram início a outra etapa da história da empresa. As vitórias em licitações no Rio de Janeiro para a construção do campus da Universidade Estadual do Rio de Janeiro (1970 e 1976), do edifício sede da Petrobras (aproveitando-se da ligação estabelecida com Ernesto Geisel, ex-comandante da Petrobras e então presidente do país), do Aeroporto Internacional do Galeão e da Usina Termonuclear Angra alçaram a CNO a um novo status (Campos, 2015; Dantas, 2007). A empresa regional nordestina agora estava entre as líderes nacionais - fato que é bastante celebrado pela própria empresa até hoje (Odebrecht, n. d. a). 
Nacionalmente consolidada após um ciclo de grandes obras no país - como o Complexo Hidrelétrico Pedra do Cavalo, em Cachoeira, na Bahia, o Sistema de Abastecimento de Água Riachão Potengi, no Ceará, e o Complexo Siderúrgico da Açominas, em Ouro Branco, Minas Gerais -, o Grupo Odebrecht se viu diante de um dilema. Com a retração do mercado da construção pesada no país - o montante encurtara pela metade entre 1975 e 1976, passando de cerca de 14 bilhões de dólares para 7 bilhões de dólares (Revista Odebrecht Informa, 1988b) - , o grupo precisava traçar possibilidades para seguir crescendo. Emílio Odebrecht, retrospectivamente, afirma que:

Vivíamos o milagre brasileiro, mas fizemos uma reflexão e concluímos que o crescimento daquele período não era sustentável. Como nossa vocação era, e continua sendo, crescer, precisávamos, então, identificar oportunidades para assegurar a continuidade de nosso crescimento e começamos a estudar três hipóteses: diversificar nossos negócios; fortalecer nossa posição em engenharia no Brasil, mediante aquisições ou ir para o exterior. Optamos pelas três. $(2008$, p. 2$)$

Em 1979, foi criada a Odebrecht Perfurações Ltda., responsável pela perfuração de poços de petróleo, e era adquirido um terço do capital da Companhia Petroquímica Camaçari, marcando o ingresso do grupo no setor petroquímico - anos mais tarde, este se tornaria o setor mais lucrativo do grupo. Dois anos depois, a Companhia Brasileira de Projetos e Obras, então sexta maior construtora brasileira, foi incorporada ao grupo. No mesmo ano, era criada a Holding Odebrecht, "voltada para a preservação das concepções filosóficas e direcionamento dos negócios" (Odebrecht, n. d. a) ${ }^{4}$. Cinco anos depois, era adquirida a Tenenge, empresa com atuação no ramo da construção pesada, com importante participação em obras na Argentina e no Paraguai - com destaque para a construção do polo siderúrgico da Acepar (Revista Odebrecht Informa, 2004b).

Durante o processo de ascensão nacional e internacional, a CNO - e todo o Grupo Odebrecht, na verdade - desenvolveu procedimentos administrativos que foram, aos poucos, compilados e cultivados como balizas edificantes da identidade da empresa. Publicados em 1983, os dois volumes da série Sobreviver, crescer e perpetuar - Tecnologia empresarial Odebrecht, escritos por Norberto Odebrecht, tornaram-se pilares amplamente difundidos

4 Hoje a organização atua em mais de oito ramos, entre os quais merecem destaque, além das já mencionadas atuações na Construção Pesada e na Petroquímica, o ramo de óleo e gás, etanol e açúcar e imobiliário (Odebrecht. n. d. a). 
entre funcionários e líderes das empresas. Preceitos e expectativas administrativas foram sistematizados no intuito de formalizar o que se pode chamar de "cultura de negócios sólida" para o processo de crescimento nacional e internacional da empresa - a Tecnologia Empresarial Odebrecht, ou TEO, conforme difundido pelo grupo (Odebrecht, 2002).

Um primeiro aspecto da cultura de negócios da CNO para a sua atuação internacional está na delegação de poder de decisão aos chamados "empresários-parceiros": colaboradores funcionais com características empreendedoras, responsáveis desde a prospecção à consolidação de negócios globais. Desses postos, são esperadas ações de verdadeiros sócios da empresa, e não de cumpridores de serviços em uma organização hierarquizada (Mazola, 2006). Esse cargo foi comumente ocupado pelos "expatriados", engenheiros brasileiros que ocupariam postos de liderança em obras locais. Mais que funções técnicas, era esperado do expatriado que se relacionasse com a nova cultura não apenas na condição de observador, mas também como agente ativo, cujos recursos de atuação se entrelaçariam com a cultura local. Essa ação se daria no contato com os diversos elementos do ambiente estrangeiro: clientes, fornecedores, órgãos de governo, formadores de opinião, entre outros (Pereira et al., 2005).

No processo de integração dos expatriados, era comum que engenheiros, ao irem solteiros a um novo país, se casassem e constituíssem família no país em questão. Símbolo dessa integração é Francisco Penteado, gerente de contrato para a execução da Termelétrica de Guacolda, no Chile (obra concluída em 1992): seu casamento com Andrea Parra, chilena, e o nascimento de seu filho, Luca, traduziram, para além de uma satisfação pessoal, o fortalecimento de um projeto de assimilação e integração da empresa com a sociedade nativa (Revista Odebrecht Informa, 1994). Paulo Welzel, gerente do contrato de Colbún-Machicura, e depois diretor de contratos da BPC, reflete que esse tipo de integração era fundamental para a perpetuação da empresa em território estrangeiro: "tínhamos de nos relacionar com autoridades chilenas, nos níveis político e estratégico, além de conhecer os aspectos administrativos e legais do funcionamento de uma empresa em outro país" (Revista Odebrecht Informa, 1994, p. 28).

Se, por um lado, os postos de comando eram ocupados pelos expatriados, por outro, a imensa maioria dos demais empregos eram preenchidos por nativos: em Charcani, no Peru, dos 876 homens que trabalhavam, apenas 22 eram brasileiros; no Chile, em Colbúm Machicura, essa proporção era 
de 12 brasileiros em um universo de 899. Esse segundo elemento do modo de atuação da CNO é explicado não por uma questão de ordem meramente econômica - de diminuição de custos - , mas sim - e principalmente por um projeto de simbiose que o grupo projetava com as comunidades locais (Revista Odebrecht Informa, 1980).

Em Angola, nos primórdios da construção da hidrelétrica de Capanda, em 1985, havia mais brasileiros que angolanos nos postos de trabalho. Em 1992, o número de funcionários angolanos era mais de cinco vezes maior que o de brasileiros (Revista Odebrecht Informa, 1995). Novamente, atuava-se estreitando os vínculos com a cultura e com a comunidade locais, em uma ação estrategicamente definida e cultivada para o sucesso no processo de internacionalização. Como sintetizou Márcio Polidoro, diretor de comunicação empresarial da CNO, "a diversidade de ambientes em que a Odebrecht opera levou a uma estratégia de comunicação bastante simples e que também a distingue: ela será sempre uma empresa local" (2010, p. 331). Casos desses tipos tornaram-se simbólicos da cultura de negócios que a CNO construía que se compreende bem naquilo que Lívia Barbosa chamou de "cultura de negócios": mesmo que incerta, "difusa e assimétrica", ela possibilitava a "comunicação negocial, a transferência tecnológica e a mudança cultural" (2002, p. 213). Tudo para a empresa "continuar sobrevivendo com sucesso". Enfim, "a cultura Odebrecht", nas palavras de Polidoro, "consolidou-se como o principal ativo intangível da Organização" (2010, p. 327).

\section{O LUGAR DA AÇÃO SOCIAL}

Um outro elemento compôs a cartilha da cultura de negócios da CNO no seu processo de internacionalização: a ação social sem finalidades lucrativas. Esse tipo de intervenção tem variadas manifestações na trajetória da $\mathrm{CNO}$ - dentro e fora do Brasil —, nem sempre remetendo aos mesmos preceitos e resultados. Além disso, ele é emblemático de um cenário mais amplo, do qual a CNO se destaca como exemplo, repleto de imagens prolíferas à compreensão do processo de assimilação da ação social pelo empresariado na história recente.

É plausível que se caracterize toda a trajetória da ação social da Odebrecht por meio do termo "filantropia", que pode ser definido, genericamente, como o fenômeno do direcionamento de riquezas para fins não 
lucrativos e socialmente relevantes para eventuais necessitados, vindo de indivíduos abastados, movidos pela vontade de ajudar ou de promover algum bem para a sociedade (Harvey et al., 2019). Entretanto, a imensa amplitude contida nesse termo - que pode compreender tanto as doações aristocráticas da Baixa Idade Média quanto a ação de modernas fundações sob financiamento de grandes corporações - torna necessário sofisticar a análise do fenômeno.

O primeiro espaço institucional da atuação social da empreiteira foi a Fundação Emílio Odebrecht, criada em 1965. Desde então, segundo seu website, ela

vem contribuindo com a sociedade para torná-la mais harmônica, solidária e com igualdade de oportunidade para todos. [...] [Focada em] regiões de vulnerabilidade e degradação ambiental, utilizando a vocação local para alavancar o crescimento econômico com conservação ambiental e inclusão social, tendo o jovem como principal agente de transformação. (Fundação Odebrecht, n. d.)

A atuação da fundação, desde sua criação até o início dos anos 1980, quando ela "deixa de ser uma entidade assistencialista voltada para os integrantes Odebrecht e se volta ao atendimento de carências da sociedade" (Fundação Odebrecht, n. d.), pode ser compreendida, conceitualmente, no que se considera uma ação filantrópica tradicional típica da América Latina (Portocarrero \& Sanborn, 2005). O estabelecimento da fundação no momento de ascensão da CNO veicula a ideia, muito comum nesse tipo de prática, de que a fartura de recursos resultante do sucesso empresarial lucrativo inferiria, de uma maneira lógica, uma maior responsabilidade - e até obrigação moral - do empresariado em combater as mazelas sociais, estabelecendo-se padrões moralmente positivos e uma identidade cidadã (Cheibub \& Locke, 2002). Tratar-se-ia de um enquadramento da empresa na sociedade sob um "gerencialismo ético", como chamou Grégoire Chamayou (2020, p. 80), que contribuiria com a salvaguarda teórica do lugar e do papel social da grande empresa. “Esse crescimento", portanto, "estimulou o da própria Fundação", nas palavras autorreflexivas com que a própria organização narra a sua trajetória, em seu website (Fundação Odebrecht, n. d.).

Mudanças importantes ocorreram na fundação de 1980 em diante: estabeleceram-se linhas de atuação estruturadas para além de seu corpo de funcionários; efetivaram-se parcerias para viabilizar ações como o Prêmio Fundação Emílio Odebrecht, em 1982, junto ao Conselho Nacional de Desenvolvimento 
Científico e Tecnológico; encarou-se o "desafio de desenvolver metodologias e estratégias próprias de intervenção social na comunidade", reestruturando a sua linha de atuação para a temática da criança e do adolescente; conquistaram-se diversas parcerias com instituições análogas, com o setor público e com a Unicef, entre 1988 e 1994 (Fundação Odebrecht, n.d.). A mudança do nome da organização para Fundação Odebrecht, em 1995, despersonalizava-a e descolava-a de seu fundador, profissionalizando-a junto ao nome do grupo empresarial mantenedor. Esse evento coroava o processo de adoção de um receituário novo, em que a ação social da CNO superou a alçada da sua fundação, operando também de forma desvinculada dessa instituição, mas sem abandoná-la. Tal modus operandi, contudo, não foi exclusivo da CNO, remetendo ao processo histórico em que todo o conjunto de relações dos empresários com a sociedade foi significativamente alterado, de 1970 em diante.

O recorte temporal das décadas de 1970 a 1980 pode ser observado, ao menos no espectro capitalista ocidental, pela crítica aos preceitos do chamado "Estado de bem-estar social"5, que teria "ido longe demais", como disse, durante um discurso, Ronald Reagan (1986, para. 8). Tornaram-se emblemáticas as políticas econômicas e sociais dos governos de Reagan, nos Estados Unidos, e de Margareth Thatcher, no Reino Unido, que serviriam de modelo para a revisão do papel do Estado em inúmeros países nas décadas subsequentes. Privatizações de empresas estatais, flexibilização das legislações trabalhistas, reformulações de programas de seguridade social, contingenciamento dos gastos públicos em nome de responsabilidade fiscal, prevalência de um paradigma tecnocrático na expectativa dos mais variados governos: a agenda pública dos países que caminhavam na adoção do receituário, nomeado "neoliberal", compôs-se de elementos como esses (Harvey, 2005).

Para a América Latina, que vira essa ascensão se consolidar em políticas estatais concretas a partir do Consenso de Washington, em 1989, e da pressão exercida por organismos multilaterais internacionais, como o Banco Mundial e o Fundo Monetário Internacional (Pereira, 2009), as reformas sociais - outrora resguardadas pelo Estado, ao menos em tese -, viram-se

5 "Estado de bem-estar social" se entende como o termo genérico para o modelo de Estado nacional que se fez responsável pelo cuidado de uma ampla variedade de flagelos e demandas sociais, como a fome, o desemprego, a seguridade médica e social, e a educação, por exemplo. Entendia-se que o Estado deveria ser a instância mediadora das mazelas sociais, como forma de garantia da estabilidade necessária ao pleno desenvolvimento econômico e democrático. Grosso modo, esse modelo foi empregado majoritariamente - ou foi ao menos inspirador - nos países capitalistas ocidentais após a Segunda Guerra Mundial (Lopes, 2018). 
indefinidas, "descartadas da agenda", como caracterizou Eli Diniz (2016, p. 67) acerca da presidência de Fernando Collor no Brasil (1990-1992).

Distanciando o olhar das particularidades históricas nacionais, é possível enxergar inúmeras semelhanças que capacitam a análise do avanço neoliberal - e da internacionalização latino-americana da CNO, ocorrida nesse cenário - como um processo coeso e orgânico. O neoliberalismo se desenhou como um "desajuste global", incorporando-se às particularidades, mas mantendo como uma constante a criação de um vácuo sobre a questão social, com a destituição do Estado como agente regulador central dessa seara (Soares, 1998). Esse espaço, contudo, seria rapidamente visado por um movimento que emergiu como teoria nos Estados Unidos, nos anos 1970, mas que se encorpou como modelo de intervenção social hegemônico nos anos 1990: o terceiro setor 6 .

Esse movimento seria composto por uma "imponente rede de organizações privadas autônomas", que, agindo "à margem do aparelho estatal", refletiria "mudanças sociais e tecnológicas", além da "contínua crise de confiança na capacidade do Estado", como comentou Lester Salamon (1998, p. 5), um dos principais articuladores da internacionalização do movimento a partir dos Estados Unidos”. O terceiro setor seria uma "revolução associativa global". A ênfase na associação como lócus do movimento remete a Aléxis de Tocqueville e é uma constante entre os referenciais teóricos do movimento, o que marca, desde o princípio, a sua forte inclinação liberal (Calegare \& Silva Júnior, 2009).

A amplitude e a diversidade, tanto da sua composição quanto das suas formas de ação - de movimentos sociais e as organizações não governamentais defensoras do meio ambiente a grandes fundações empresariais de interesses múltiplos, por exemplo - , são características do terceiro setor ${ }^{8}$. As imprecisões sobre quem o compõe, como ele atua e quais as suas finalidades são tão marcantes que há autores, como Carlos Montaño (2005), que não

6 A definição nominal do terceiro setor divide a sociedade em setores: o primeiro seria o Estado — de gênese e finalidade públicas; o segundo seria o mercado - esfera privada, designada ao lucro. O primeiro setor se mostrara incapaz de lidar de forma apropriada com a questão social como mostrara a falência do welfare state; o segundo, por ser privado em seu fim, também não poderia se responsabilizar pelo bem-estar público. Conceitua-se, então, o terceiro setor, esfera de natureza privada — porque estaria nos próprios indivíduos —, mas com finalidade pública porque visaria ao bem-estar de toda a sociedade. O terceiro setor é privado, porém, público, como caracteriza a definição de um dos seus arautos no Brasil, Rubem César Fernandes (1994).

7 Salamon foi diretor do Center for Civil Society Studies, da John Hopkins University, além de diretor do Projeto Comparativo do Setor não Lucrativo, que produzia informações sobre o terceiro setor em mais de 20 países ainda nos anos 1990 (Alves, 2002).

8 Sobre a questão de quais seriam as organizações componentes do terceiro setor, ver Calegare (2005, pp. 30-36). 
hesitam em afirmar que seus entusiastas só encontram unidade sincera na perene crítica da ação do Estado, alinhando-se aos pressupostos neoliberais hegemônicos. O terceiro setor faria o que o Estado não fez e seria reflexo da desconfiança no que o Estado seria capaz de fazer. A sua ascensão a fenômeno global, nos anos 1990, teria se desenhado por impulso da própria "sociedade civil" $^{\prime \prime}$, que teria se organizado para "tomar em suas próprias mãos" a resolução de seus flagelos e direitos, com incentivo de agente externos, como as instituições religiosas e o Banco Mundial, e a retração da presença do Estado, que abria um espaço a ser ocupado (Salamon, 1998, p. 7).

Em paralelo ao desenvolvimento desse novo agenciamento do bem-estar social, as empresas viram a sua relação com o Estado e com a sociedade alterar-se profundamente. No Brasil, com a deterioração política e econômica da Ditadura Militar, o empresariado que, até então, se mostrara próximo do aparelho estatal, assumiu para si o corolário argumentativo neoliberal, enxergando no Estado o responsável pelo cenário crítico de então (Bianchi, 2001).

Contudo, a despeito do descontrole inflacionário, da estagnação produtiva e do desenlace da transição para a Nova República, na década de 1980, não havia ainda, por parte das empresas, a solidez institucional para a ocupação efetiva dos novos espaços sociais por elas mesmas almejados. As várias facetas da relação empresas-Estado-sociedade encontravam-se em um momento nebuloso: o anseio pela retração da ingerência econômica do Estado, por exemplo, conflitava com as já costumeiras práticas de financiamento público herdadas do modelo desenvolvimentista; a manifesta vontade de liberalização do mercado interno a empresas estrangeiras, em outro caso, chocava-se com os receios das entidades de classe tradicionalmente mais protecionistas (Diniz, 2016). A saída pela internacionalização, como dito, foi uma das abordagens da CNO para esse cenário, no qual a ação social ocuparia lugar de destaque.

Diversas associações e entidades de classe emergiram nas décadas de 1980 e 1990, almejando superar a "crise de representatividade" do empresariado e solidificar o ideário liberal que se popularizava (Bianchi, 2001, p. 49). Uma delas foi o Instituto Ethos de Responsabilidade Social, que se

9 Para a maior parte dos entusiastas do terceiro setor, "sociedade civil" é interpretada, genericamente, como o campo daqueles não inseridos na esfera estatal. Suas caracterizações, em geral, são politicamente insípidas, ignorando-se disputas de interesses e as possíveis interrelações com o Estado e com o mercado. Sobre essa definição, ver Montaño (2005, pp. 120-130) e Corry (2010, pp. 17-19). 
formalizou, em 1998, como uma associação empresarial sem fins lucrativos, voltada para a reestruturação da relação do empresariado com os dilemas sociais - tornando-se uma das principais cultivadoras dos preceitos do terceiro setor no país. O Ethos defendia uma revisão da função social dos empresários, na medida em que entendia a ação social como amplamente vinculada aos interesses lucrativos da empresa (Andrade, 2014).

A defesa do conceito de "responsabilidade social empresarial", principal campanha do Ethos, deu-se no entendimento de que a ação social não é uma imposição legal ao empresário, mas também não se explica pela motivação moral característica da filantropia. A responsabilidade social empresarial é defendida como um "instrumento gerencial" útil nos cenários de redefinição do papel da empresa em um mercado cada vez mais competitivo (Cheibub \& Locke, 2002). Esse conceito deveria ser introduzido no meio empresarial e na sociedade como um todo, a fim de que fosse assimilado e cultivado - com estratégias de difusão nos meios de comunicação e na academia, por exemplo ${ }^{10}$.

Ainda que varie a natureza do interesse - que pode ir do marketing social ao estabelecimento de programas educativos ao corpo de funcionários, por exemplo - , o modelo de intervenção social empenhado pelo Ethos redefine a percepção do empresariado sobre o lugar do lucro e da ação humanitária em seus afazeres: superando a divisão estática entre a filantropia e a atividade lucrativa, emerge uma "posição progressista", marcada pela estratégia gerencial que funde o lucro e a ação social na mesma engrenagem (Cheibub \& Locke, 2002, pp. 280-286).

A ação do Ethos, contudo, apenas emergiu concretamente para sistematizar ideias e práticas empresariais que já vinham sendo pautadas há anos, ainda que de forma disforme e errática. O cenário que efetivou a reestruturação dos parâmetros de intervenção social empresarial já se manifestara no interior das organizações, antes de surgir a reformulação institucional do terceiro setor: o anseio por qualificar as relações públicas e o marketing em um contexto de intensa concorrência, aquisições e privatizações; o empenho em construir uma narrativa útil na legitimação da empresa ante aos seus funcionários; o apelo para a criação de terrenos férteis para a atividade lucrativa em meio a períodos de instabilidade e crise (Chamayou, 2020). Todos esses elementos são essenciais na explicação do impulso de

10 Como exemplos das cartilhas produzidas pelo Ethos, ver Ethos (1999) e Camarotti e Spink (2003). 
reformulação da gestão social dos empreendimentos privados (Chamayou, 2020; Dardot \& Laval, 2016).

Essa nova gestão empresarial já se manifestara na cultura de negócios da "Tecnologia Empresarial Odebrecht". Revendo seu lugar na sociedade, a CNO, como toda essa nova e popular vertente administrativa, zelava pelo lugar ocupado pelos empresários no imaginário social e iniciava os experimentos da ação social como instrumento gerencial, para além da atuação especializada da sua fundação. O que foi sistematizado pelo Ethos em 1998, no caso da CNO - e de outras empresas - já era preocupação desde o final dos anos 1970. Para além da relevância do enraizamento familiar e cultural do corpo de funcionários nos países projetados para a realizações de empreendimentos, a CNO percebeu que, para "sobreviver, crescer e perpetuar", fazia-se necessária a implementação de práticas concretas de intervenção social, em nome do bem-estar de seus funcionários e das comunidades impactadas pelas suas obras. Conforme explica o website da empresa,

a atuação sustentável da Odebrecht tem compromisso com o desenvolvimento social das Comunidades das áreas de influência dos projetos. Ampliamos os benefícios às comunidades do entorno dos nossos Negócios, harmonizando a conquista dos resultados econômicos com o desenvolvimento social. (Odebrecht, n. d.c)

As ações sociais alimentariam as atividades lucrativas da empresa na medida em que contribuiriam para "influenciar o processo de aceitação pelos grupos sociais com os quais irá interagir no cotidiano de suas operações", segundo Polidoro (2010, p. 330). Além disso, essas intervenções poderiam, pontualmente, desconstruir ideias como a cisão de classes, em que os empresários são projetados como diferentes dos assalariados ${ }^{11}$ ou a de que à empresa cabia somente o lucro, sendo o campo social estranho a ela ${ }^{12}$. Os funcionários impactados pelas ações sociais da empreiteira não trabaIham mais para a empresa, mas com a empresa, como iguais em interesses, responsabilidades, ganhos e perdas. As comunidades beneficiadas pelos programas de valorização do cotidiano, do meio ambiente, da cultura e da

11 Fred Costa, um dos responsáveis pelo programa em Charcani, entre 1986 e 1988, relembra, ao enfrentar um contexto de forte greve sindical no Peru: "Dialogamos com os sindicatos, demonstrando que a cultura empresarial da Odebrecht não contrapõe empresários e trabalhadores, e isso nos tornou parceiros, envolvidos em decisões, realizações e resultados" (Revista Odebrecht Informa, 1994, p. 25).

12 O que contribui com a estratégia de apresentação da empresa como um "emaranhado contínuo de relações", identificada por Chamayou (2020, p. 162) como parte do processo de realocação de critérios para a apreciação social da grande empresa, com maior ênfase a partir da década de 1980. 
memória locais não veriam na empresa um ente estranho, mas uma parceira frutífera, catalisadora do bem-estar e do desenvolvimento. Os funcionários e as demais pessoas próximas da CNO conceberiam os seus interesses pessoais como coesos com os interesses da empresa.

A ação social da CNO virou parte essencial da cartilha gerencial da empresa no Brasil, integrando regiões e culturas de comunidades envolvidas com os empreendimentos da empreiteira (Odebrecht, n. d. c). Entretanto, ao que nos interessa mais, a ação social tornou-se parte do receituário da internacionalização, subindo mais um degrau em sofisticação, na medida em que buscava diálogo e a aceitação de culturas, línguas e histórias estrangeiras. Para além dos já citados exemplos do caso peruano, as ações sociais de uma CNO internacionalizada tornaram-se rotina. Variando em enfoque e dimensão, elas mantiveram o intuito orgânico de se estabelecer como ferramentas gerenciais essenciais para o êxito na lucratividade dos empreendimentos da empresa. O lançamento de Arequipa, em 1988, que encampou a ação social pioneira no país que estreou a atuação internacional da CNO, foi apenas o primeiro passo do binômio internacionalização-ação social, que se repetiu, quase como uma fórmula, em praticamente todo país onde a empreiteira atuou.

Se a CNO adentraria o mercado venezuelano em 1992, iniciando uma trajetória de mais de 30 obras no país, ações sociais semelhantes às observadas no caso peruano seriam realizadas sem falha. Em 1992, foi iniciada a construção do Shopping Centro Lago Mall, em Maracaibo, segunda maior cidade venezuelana. Nessa mesma região, uma década depois, seria anunciado o desenvolvimento do Projeto Agrário Socialista da Planície de Maracaibo, que contaria com uma área de 27 mil hectares e com a presença de 11 mil famílias, dividindo-se em cinco núcleos urbanos planejados, dotados de sistemas de irrigação para produção de 475 mil toneladas de alimento, e estendendo-se da fronteira colombiana às proximidades de Maracaibo (Relatório anual, 2008).

Salta aos olhos que, no anseio de melhor efetivar a assimilação das boas ações da empresa na Venezuela, a CNO - indiscutivelmente uma instituição privada capitalista - não hesitou em adotar o "socialismo" no nome de seu projeto, aumentando os veios de entrada na cultura e política do país caracterizado por esse termo em seu regime. Dois anos depois, a CNO lançava o livro Los Wayuu, contanto a história e a realidade do povo Wayuu, um dos maiores povos indígenas da Venezuela e os principais beneficiários do 
Projeto Agrário Socialista, com textos em espanhol e em wayuukana, idioma dos Wayuus (Relatório anual, 2010).

Entre 2001 e 2002, foram lançadas três edições de uma obra trilíngue, com texto do poeta Luis Alberto Crespo e projeto editorial de Ernesto Armitano. Venezuelas ilustra, com mais de 400 fotos, os predicados naturais, arquitetônicos e culturais da Venezuela, lançado em um primoroso trabalho editorial (Odebrecht, n. d. b). Em 2007, foi lançado outro livro: Il Puente sobre el Río Orinoco - Realizando un sueño de integración venezolana, uma obra autorreflexiva, que narra a experiência da construção, pela CNO, da segunda ponte sobre o rio Orinoco, discutindo a sua relevância histórica para o projeto de integração e infraestrutura venezuelano. A ponte bimodal teve um investimento de 1,28 bilhões de dólares e, além de ser considerada uma maravilha da engenharia, com 3.156 metros de comprimento, quatro faixas para o trânsito de veículos e uma via férrea, foi responsável por interligar os estados brasileiros Amazonas e Roraima com os portos de exportação da Venezuela no mar do Caribe (Relatório anual, 2007). A ponte fora inaugurada um ano antes do lançamento do livro, em 2006, com a presença comemorativa dos presidentes Lula, do Brasil, e Hugo Chávez, da Venezuela.

Uma celebração semelhante, mas ainda mais vistosa, ocorrera em 1998, no salão nobre da Casa de la Cultura, em Quito, no Equador. Fabián Alarcón, o então presidente equatoriano, Renato Baiardi, líder empresarial da CNO, e Luiz Mameri, superintendente da construtora em solo equatoriano, na noite de 22 de janeiro, cortavam a fita que inaugurava a exposição promovida pela empreiteira, em comemoração aos dez anos de sua atuação no país. $\mathrm{O}$ evento contou com mais de 500 convidados, com a presença de autoridades civis, militares, ministros e membros de Juntas Diretivas dos clientes. De um lado, havia painéis expositivos com as obras realizadas pela construtora em solo andino; do outro, estavam expostas obras de arte. Ali realizou-se o Concurso Nacional de Jornalismo Talentos Anônimos, programa social financiado pela empreiteira, que invitava escritores a narrarem as vidas de personalidades anônimas que "trouxeram benefícios morais ou materiais ao país". Os três melhores seriam premiados, além de terem seus textos transformados em um livro ilustrado a ser editado pela construtora ${ }^{13}$. "O livro é um exemplo da preocupação da Organização Odebrecht com a

13 Mais tarde, devido ao sucesso da iniciativa, foram aumentados para dez os trabalhos selecionados, segundo apontado no website da organização (Odebrecht, n. d. b). 
preservação do patrimônio cultural das comunidades em que atua", reflete a empresa (Odebrecht, n. d. b).

No mesmo evento, foi firmado o acordo "Educar é construir", entre a CNO e Jaramillo Paredes, ministro da Educação, Cultura e Desportos do Equador. O plano teria por objetivo a instalação, em todos os canteiros da CNO no país, da infraestrutura necessária para a promoção, por parte da empresa, de aulas de alfabetização aos trabalhadores das obras - ao Ministério, caberiam a metodologia educativa e a manutenção dos projetos após o término das obras, numa dinâmica à qual a empresa já estava acostumada por experiências anteriores (Revista Odebrecht Informa, 1986).

O evento em Quito, com toda a sua pompa, representava o ponto alto da trajetória da CNO em território equatoriano, dez anos após o início das obras de irrigação que visaram tornar produtiva uma área de até 45 mil hectares, na Península de Santa Elena - espaço estratégico para o desenvolvimento da agricultura local, que, sozinha, representava $12 \%$ do produto interno bruto do país. Para além de atender à crescente demanda interna de alimentos, o aproveitamento das águas do rio Daule contribuiria para o desenvolvimento industrial e turístico regional, o que poderia atribuir à Santa Elena um papel de novo polo de ocupação populacional, aliviando o impacto migratório para Quito e Guayaquil (Revista Odebrecht Informa, 1988a). A obra, orçada em 200 milhões de dólares, contou com o financiamento do Banco do Brasil, através da Carteira de Comércio Exterior do Banco do Brasil, tendo como contrapartida uma exportação de bens de capital brasileiros na ordem de 48 milhões de dólares e de bens intermediários e de consumo durável de, aproximadamente, 33 milhões de dólares. O apoio dado pelo Estado brasileiro foi ainda assinalado por Roberto Abdenur, representante máximo da embaixada brasileira em Quito, responsável por detectar o potencial da obra e por criar redes de contato - missões comerciais e feiras de catálogos, por exemplo - entre o empresariado nacional e o governo equatoriano (Revista Odebrecht Informa, 1988b).

A intensa presença política de líderes importantes do Brasil e do Equador, nesse caso, aprofunda ainda mais a relevância da ação social da empresa como ferramenta de sucesso no seu projeto de internacionalização - como também ilustraram os casos peruano e venezuelano. A ação social internacional da CNO ganha novos contornos de relevância, na medida em que a presença da empreiteira se fazia importante no firmamento de negociações econômicas e diplomáticas entre estados latino-americanos, 
ansiosos pelo estreitamento das suas relações. Em outras palavras, o impacto da ação social ganharia cores políticas, tornando-se mais do que um êxito restrito ao lucro da CNO.

Não só na América Latina foi praticada a ação social da CNO. A presença da Odebrecht no continente africano, por exemplo, iniciada com a construção da hidrelétrica de Capanda, em Angola, no final dos anos 1980, desenrolou-se em paralelo a intervenções sociais muito semelhantes às observadas na América. Em 1991, foi lançado, com patrocínio da Odebrecht, Angola e a expressão de sua cultura material. O livro traça um perfil da multifacetada cultura do país, a partir da análise de 63 peças simbólicas das sete grandes comunidades culturais angolanas: Bakongo, Ambundu, Ovimbundu, Cokwe, Ovingangela, Ociwambo e Khoisan. São estudados amuletos, máscaras, totens, estatuetas, instrumentos musicais e objetos utilitários, todos pertencentes ao acervo do Museu Nacional de Antropologia de Angola, em Luanda. Cada peça é apreciada em sua individualidade artística e em seu devido lugar social, com pesquisa e texto da antropóloga Ana Maria de Oliveira, diretora do Museu, e fotografias de Mário Cravo Neto. O prefácio de Ivan Cannabrava, embaixador do Brasil em Angola, na época, reflete a importância do acervo na valorização do patrimônio cultural do país (Oliveira, 1991). Sem finalidade lucrativa, é mais um exemplo da ação social estratégica da Odebrecht, inexoravelmente vinculada aos seus empreendimentos empreiteiros.

A expansão da CNO aos Estados Unidos, que seguiu os mesmos parâmetros observados nos demais casos elencados, mostra que não só países periféricos com notáveis carências sociais receberam ações sociais da empreiteira. A construção do Metromover - um sistema de transporte elevado composto por unidades operadas automaticamente à distância -, em Miami, marcou a chegada da empresa ao país, em 1990 (Odebrecht, 2016). Desde então, a sua presença se aprofundou no país, sobretudo no estado da Flórida, com obras como a Ponte Merril Barber, em 1995, e o ginásio da equipe de basquete Miami Heat — hoje American Airlines Arena —, em 1999. A ação social, como parte inconteste do receituário da atuação internacional da empresa, manifestou-se na medida em que a sua presença se acrescia, conforme ilustram os apoios financeiros a entidades do terceiro setor, como a Best Buddies e a YMCA (Relatório anual, 2008).

Esses exemplos são apenas uma pequena parte da totalidade de ações sociais conduzidas pela CNO em seu processo de internacionalização. Como bem ilustra o mapa abaixo - que destaca o continente americano com 
Figura 1. Mapa das obras da CNO e ações sociais do Grupo Odebrecht (2007 e 2008) dados de 2007 e 2008 -, em praticamente todos os países onde houve obras da CNO, existiram ações sociais correlatas - da própria empreiteira ou de alguma empresa subsidiária do Grupo Odebrecht.

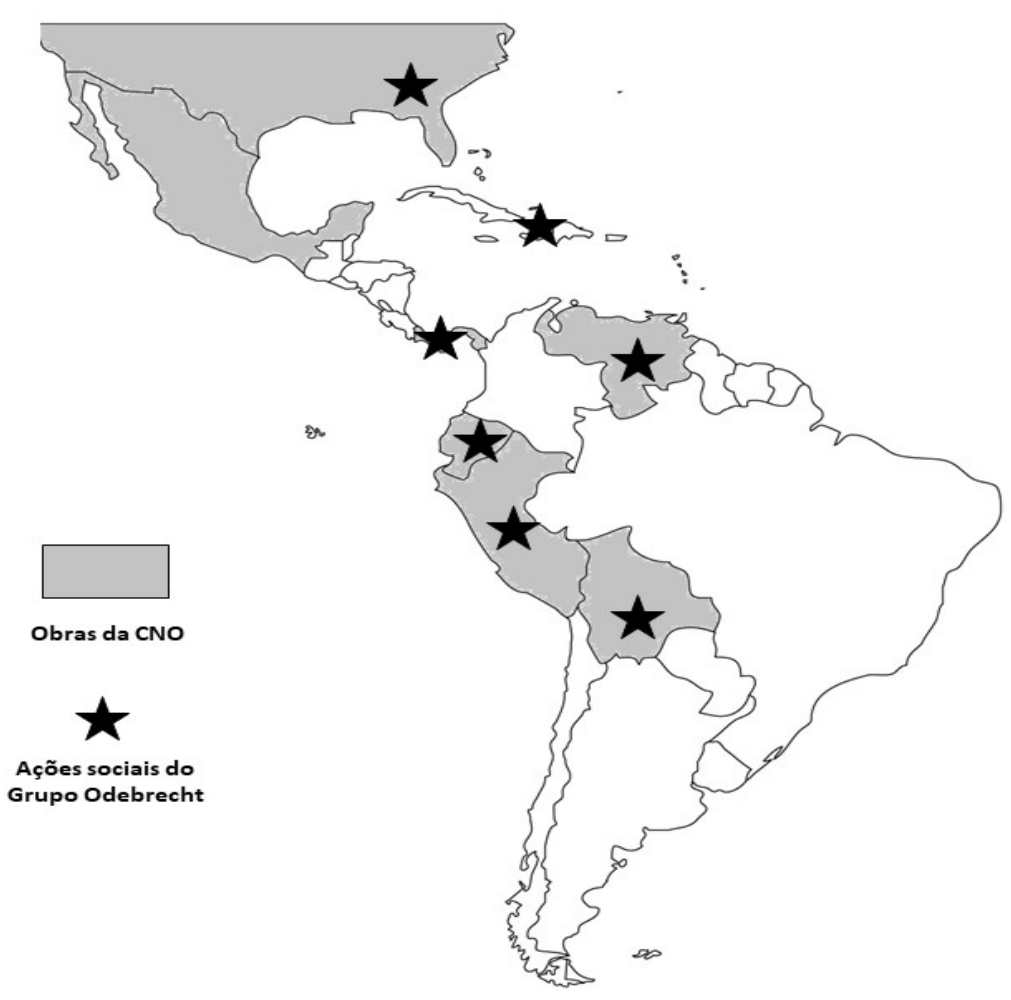

Para Emílio Odebrecht, nada mais natural do que essa ambivalência de ações. A ação empresarial lucrativa requer a intervenção social sustentável, retroalimentando a primeira com o preparo de terrenos férteis para a ampliação de mercados e empreendimentos em potencial:

As empresas que têm por rumo a perpetuidade devem internalizar a sustentabilidade econômica, social e ambiental como um valor próprio, indistinto de sua sobrevivência, como autoexigência anterior às leis dos estados e às solicitações dos clientes. $E$, aqui, não se trata apenas de adiantar-se ao mercado, para sair na frente, mas de compreender que, sem isso, não haverá mercado nem empresas. (Relatório anual, 2008, p. 12)

A responsabilidade social empresarial, sistematizada no final dos anos 1990, no esteio do terceiro setor como padrão de intervenção social emergente, é fruto de um longo processo histórico, no qual as empresas têm lugar central. A experiência da CNO — desde as suas ações sociais primárias 
no Brasil até o estabelecimento de um padrão de intervenção social como instrumento estratégico de êxito internacional — é uma imagem desse processo. A história global recente, enredada pelos característicos marcos do neoliberalismo, requer que se revisite os pressupostos da pesquisa histórica, revendo os lugares sociais do Estado e das empresas, com todos os problemas políticos e metodológicos que isso acarreta. Com efeito, a experiência da CNO desvela os meandros da globalização, da diplomacia e do lugar do bem-estar social no mundo contemporâneo, demonstrando que o estudo crítico das empresas se faz imprescindível na pesquisa histórica atual.

\section{CONCLUSÕES}

A CNO está presente em mais de 40 países, em cinco continentes, configurando-se como uma das maiores multinacionais da construção pesada no mundo, e uma das mais internacionalizadas empresas brasileiras. O processo dessa internacionalização infere inúmeras possibilidades de análise histórica: o impacto econômico no Brasil e nos países visados pela empresa; os enlaces com as políticas externas dos governos, como fatores de impulso ou de freio à internacionalização; as variáveis para a compreensão do caso como elemento constituinte - ou não — do processo de desenvolvimento econômico de blocos regionais.

Entre todos, elegemos a peremptória ocorrência da ação social não diretamente lucrativa como fator edificante do modelo de internacionalização da CNO. Notando a relação intrínseca da manifestação dessas ações sociais com os empreendimentos lucrativos da empresa, buscou-se mostrar que não há coincidência ou idealismo ético na coligação desses elementos. Retomando-se a trajetória da ação social empresarial nas últimas décadas, com destaque para a emergência do terceiro setor, fica claro que o empresariado se tornou um agente central nesse espaço, entendido como uma extensão estratégica e vinculante para a viabilização das suas atividades lucrativas.

É possível traçar diferentes abordagens analíticas dessa percepção. Com o empresariado se apropriando da intervenção social, outrora predominantemente estatal, podem ser apreciados tanto os impactos qualitativos dessa nova ação quanto os seus impactos políticos. Com efeito, a variedade de matérias resultantes das ações sociais da CNO vai de projetos 
ambientais e agrícolas bem planejados - como o da Cordilheira Escalera e o de Maracaibo - a livros com importantes acervos e reflexões patrimonialistas - como Arequipa, Venezuelas e Angola - , o que infere diferentes impactos e caminhos interpretativos.

Ainda que não busquemos aqui uma avaliação aprofundada sobre a efetividade desses projetos, é seguro dizer que não se destacam deles aspectos visivelmente negativos. Assim, como colocado por Zairo Cheibub e Richard Locke (2002), pode-se sugerir como reflexão final que, mais relevante do que a análise qualitativa dos projetos - que é inevitavelmente relativa e condicionada - é a análise dos impactos políticos desse tipo de ação social. Sob a batuta do Estado, o campo da questão social é entendido como uma esfera pública, em ampla relação com o aspecto político marcante do Estado democrático. Ao ser encampado pela ação empresarial notadamente privada - , esvazia-se o sentido público da esfera social, que se torna paulatinamente despolitizada e sujeita aos meandros operacionais de concepções gerenciais cultivadas com fim último de melhora na performance lucrativa empresarial — sejam maiores, sejam menores a efetividade e a qualidade da ação em questão.

A ação social da CNO, "como um valor próprio, indistinto de sua sobrevivência", como disse Emílio Odebrecht, é uma imagem de um processo mais amplo: o fato de ele ser característico da estratégia de internacionalização da empresa, mostrando-se presente em variados países e continentes, sinaliza que, para além de um padrão de gerenciamento empresarial brasileiro, há uma tendência transnacional e global nesse tipo de ação. Essa convergência requer estudos mais aprofundados, que coloquem na ação empresarial o escopo de análise para a compreensão da história recente. $A$ variedade de desafios que essa seara de estudos implica aos historiadores vai do trabalho sob contrato de empresas à difícil empreitada do trabalho independente - sobretudo no que concerne ao acesso à documentação de arquivos privados. Reconhecendo-se nessa última esfera, sublinhada em importância pelo caso particular aqui desenvolvido, este texto se propôs, enfim, a ser apenas mais uma contribuição para essa temática. 


\section{REFERÊNCIAS}

Alves, M. A. (2002). Terceiro setor: as origens do conceito. ENANPAD, 26.

Andrade, L. M. (2014). Neoliberalismo e hegemonia burguesa: ação social empresarial através dos Institutos Ethos de Responsabilidade Social Empresarial e Empresas e Gife (Grupos de Institutos, Fundações e Empresas (dissertação de mestrado em Ciências Sociais, Universidade Estadual Paulista, Brasil).

Barbosa, L. (2002). Globalização e cultura de negócios. Em A. M. Kirchner, E. Gomes, \& P. Cappelin (orgs.), Empresa, empresários e globalização (pp. 211-226). Relume-Dumará/FAPERJ.

Bianchi, A. (2001). Hegemonia em construção: a trajetória do Pensamento Nacional de Bases Empresariais. Xamã.

Calegare, M. (2005). A transformação social no discurso de uma organização do terceiro setor (dissertação de mestrado em Psicologia Social e do Trabalho, Universidade de São Paulo, Brasil).

Calegare, M., \& Silva Júnior, N. (2009). A "construção" do Terceiro Setor no Brasil: da questão social à organizacional. Psicologia Política, 9(17), 129-148.

Campos, P. H. (2015) Estranhas catedrais: as empreiteiras brasileiras e a Ditadura civil-militar (1964-1988). EDUFF.

Camarotti, I., \& Spink, P. (2003). O que as empresas podem fazer pela erradicação da pobreza. Instituto Ethos.

Chamayou, G. (2020). A sociedade ingovernável: uma genealogia do liberalismo autoritário. Ubu Editora.

Cheibub, Z., \& Locke, R. (2002). Valores ou interesses. Reflexões sobre a responsabilidade social das empresas. Em A. M. Kirchner, E. Gomes, \& P. Cappelin (orgs.), Empresa, empresários e globalização (pp. 279-291). Relume-Dumará/FAPERJ.

Corry, O. (2010). Defining and theorizing the third sector. Em R. Taylor (ed.), Third Sector research (pp. 11-20). Springer, International Society for Third-Sector Research. https://doi.org/10.1007/978-1-4419-5707-8_2

Dantas, R. M. (2007). Odebrecht - a caminho da longevidade saudável? (dissertação de mestrado em Administração, Universidade Federal do Rio de Janeiro, Brasil). 
Dardot, P., \& Laval, C. (2016). A nova razão do mundo: ensaio sobre a sociedade neoliberal. Boitempo.

Diniz, E. (2016). Empresariado e projeto neoliberal na América Latina: uma avaliação dos 133 anos 80. Em J. Szwako, R. Moura, \& P. D'avila Filho (orgs.), Estado e sociedade no Brasil: a obra de Renato Boschi e Eli Diniz (pp. 133-156). CNPq, FAPERJ, INCT/PPED, Ideia D.

Fernandes, R. C. (1994). Privado, porém público: o terceiro setor na América Latina. Relume-Dumará.

Draibe, S. (1985). Rumos e metamorfoses: estado e industrialização no Brasil, 1930-1960. Paz e Terra.

Ferraz Filho, G. T. (1981). A transnacionalização da grande engenharia brasileira (dissertação de mestrado, Universidade Estadual de Campinas, Brasil).

Fundação Odebrecht. (n. d.). Linha do tempo. https://www. fundacaoodebrecht.org.br/a-fundacao/linha-do-tempo/index.html

Harvey, D. (2005). A brief history of neoliberalism. Oxford University Press. https://doi.org/10.1093/oso/9780199283262.001.0001

Harvey, C., Maclean, M., \& Suddaby, R. (2019). Historical perspectives on entrepreneurship and philanthropy. Cambridge University Press. https://doi.org/10.1017/S0007680519000953

Instituto Ethos. (1999). O que as empresas podem fazer pela educação. CENPEC/Instituto Ethos.

Lopes, E. A. (2018). Welfare State: teoria e história. CRV. https://doi. org/10.24824/978854442635.7

Mazola, H. J., \& Oliveira Junior, M. (2006). Compartilhando conhecimento na internacionalização de serviços de engenharia: estudo de caso da Construtora Norberto Odebrecht. $30^{\circ}$ Encontro da Anpad.

Montaño, C. (2005). Terceiro Setor e questão social: crítica ao padrão emergente de intervenção social. Cortez.

Odebrecht, E. (2008). A atuação internacional da Organização Odebrecht. Discurso de abertura do XX Fórum Nacional Brasil _ Um novo mundo nos trópicos: 200 anos de independência econômica e 20 anos de Fórum Nacional. 26-30.

Odebrecht, N. (2002). Sobreviver, crescer e perpetuar - Tecnologia Empresarial Odebrecht V.1. V.2. V.3. Fundação Odebrecht. 
Odebrecht. (n. d. a). A Odebrecht. História. https://www.odebrecht.com/ pt-br/organizacao-odebrecht/historia. Internet Archive: https://web. archive.org/web/20200511160700/https://www.odebrecht.com/ pt-br/organizacao-odebrecht/historia

Odebrecht. (n. d. b). Cidades e regiões. https://www.odebrecht. com/ptbr/sustentabilidade/politica-sobre-sustentabilidade/ valorizacao-da-cultura/cidades-e-regioes

Odebrecht (n. d. c). Sustentabilidade. https://www.odebrecht.com/ pt-br/sustentabilidade. Internet Archive: https://web.archive. org/web/20200511143106/https://www.odebrecht.com/pt-br/ sustentabilidade

Odebrecht. (2016). Odebrecht conquista novo contrato nos Estados Unidos. https://www.odebrecht.com/pt-br/comunicacao/noticias/ odebrecht-conquista-novo-contrato-nos-estados-unidos. Internet Archive: https://web.archive.org/web/20170325172810/ http://www.odebrecht.com/pt-br/comunicacao/noticias/ odebrecht-conquista-novo-contrato-nos-estados-unidos.

Odebrecht S. A. (2014). IIRSA SUR. http://www.odebrechtlatinvest.com/ activos/iirsa-sur.html. Internet Archive: https://web.archive.org/ web/20200128115845/http://www.odebrechtlatinvest.com/activos/ iirsa-sur.html

Odebrecht S. A. (2007). Relatório anual 2006/2007. Odebrecht S. A. https:// www.novonor.com.br/sites/default/files/port_ra_impressao_05_ jun_2007.pdf Relatório anual 2007/2008. Odebrecht S. A. https:// www.novonor.com.br/sites/default/files/relatorio_anual_2008_ portugues.pdf

Odebrecht S. A. (2010). Relatório anual 2009/2010. Odebrecht S. A. https://www.novonor.com.br/sites/default/files/ relatorio_anual_2011_pt.pdf

Oliveira, A. M. (1991). Angola e a Expressão de sua Cultura Material. Odebrecht.

Pereira, J. (2009). O Banco Mundial como ator político, intelectual e financeiro (1944-2008) (tese de doutorado em História, Universidade Federal Fluminense, Brasil). 
Pereira, N., Pimentel, R., \& Kato, H. (2005). Expatriação e estratégia internacional: o papel da família como fator de equilíbrio na adaptação do expatriado. Revista de Administração Contemporânea, 9(5), 53-71. https://doi.org/10.1590/S1415-65552005000400004

Polidoro, M. (2010). Odebrecht - A comunicação como processo e a construção de culturas. Em M. Marchiori (org.), Comunicação e organização: reflexões, processos e práticas (pp. 325-334). Difusão Editora.

Portocarrero, F., \& Sanborn, C. (eds.). (2005). Philanthropy and Social Change in Latin America. Harvard University Press.

Reagan, R. (1986). Radio Address to the Nation on Welfare Reform. Ronald Reagan presidential library and museum. https://www.reaganlibrary. gov/research/speeches/21586a

Revista Odebrecht Informa. (1980). 25.

Revista Odebrecht Informa. (1986). 37.

Revista Odebrecht Informa. (1988a). 40.

Revista Odebrecht Informa. (1988b). 41.

Revista Odebrecht Informa. (1994a). 61.

Revista Odebrecht Informa. (1994b). 65.

Revista Odebrecht Informa. (1995). 68.

Revista Odebrecht Informa. (1998). 86.

Revista Odebrecht Informa. (2004a). 112.

Revista Odebrecht Informa. (2004b). Edição histórica 60 anos.

Salamon, L. (1998). A emergência do terceiro setor — uma revolução associativa global. Revista de Administração, 33, 5-11.

Soares, L. T. (1998). Ajuste neoliberal e desajuste social na América Latina. UFRJ. 